\title{
Karyotype, C-and fluorescence banding pattern, NOR location and FISH study of five Scarabaeidae (Coleoptera) species
}

\author{
Edgar Bione ${ }^{1}$, Rita de Cássia de Moura ${ }^{1,2}$, Reginaldo de Carvalho ${ }^{1}$ and Maria José de Souza ${ }^{1}$ \\ ${ }^{1}$ Universidade Federal de Pernambuco, Centro de Ciências Biológicas, Departamento de Genética, \\ Recife, PE, Brazil. \\ ${ }^{2}$ Universidade de Pernambuco, Instituto de Ciências Biológicas, Departamento de Biologia, Recife, \\ PE, Brazil.
}

\begin{abstract}
Meiotic chromosomes obtained from members of the coleopteran subfamilies Rutelinae and Dynastinae were studied using standard and silver nitrate staining, C-banding, base-specific fluorochromes and fluorescent in situ hybridization (FISH). The study presents detailed karyotipic descripitions of three Rutelinae species (Geniates borelli, Macraspis festiva and Pelidnota pallidipennis), and two Dynastinae species (Lygirus ebenus and Strategus surinamensis hirtus) with special emphasis on the distribution and variability of constitutive heterochromatin and the nucleolar organizer region (NOR). We found that for G. borelli, $P$. pallidipennis, L. ebenus and $S$. $s$ hirtus the karyotype was $2 \mathrm{n}=20\left(9 \|+\mathrm{Xy}_{\mathrm{p}}\right)$, with $\mathrm{G}$. borelli, $P$. pallidipennis and L. ebenus showed meta-submetacentric chromosomes which gradually decreased in size. For Macraspis festiva the karyotype was $2 n=18\left(8 I I+X y_{p}\right)$. In $L$. ebenus we found that the NOR was located on an autosome, but in the other four species it occurred on the sex bivalents. In all five species the constitutive heterochromatin $(\mathrm{CH})$ was predominantly pericentromeric while the $X$ chromosomes were almost completely heterochomatic, although $\mathrm{CMA}_{3} / \mathrm{DA} / \mathrm{DAPI}$ staining showed intra and interspecific variation in the bright fluorescence of the constitutive heterochromatin. The FISH technique showed rDNA sites on the $\mathrm{X}$ chromosome of the Rutelinae species.
\end{abstract}

Key words: karyotype, constitutive heterochromatin, NORs, rDNA sequences.

Received: August 7, 2004; Accepted: January 15, 2005.

\section{Introduction}

The coleopteran family Scarabaeidae is made up of a cosmopolitan group of approximately 2,300 genera and 27,000 species worldwide distributed with a highly conserved diploid chromosome number $(2 n=20)$ and Xy type 'parachute' $\left(\mathrm{Xy}_{\mathrm{p}}\right)$ sex-determining mechanism, although there is variation in chromosome morphology (Smith and Virkki, 1978; Yadav and Pillai, 1979; Colomba et al., 1996). Neotropical and Brazilian representatives of the scarabaeid subfamilies Rutelinae and Dynastinae have been extensively studied taxonomically (Endrödi, 1985; Morón et al., 1997) and it is known that more than $50 \%$ of the species from these subfamilies possess the standard karyotype, although variations in chromosome number have been observed with the chromosome number ranging from $2 \mathrm{n}=18$ to $2 \mathrm{n}=22$ in the subfamily Rutelinae (Smith

Send correspondence to Rita Moura. Universidade de Pernambuco, Instituto de Ciências Biológicas, Departamento de Biologia, Rua Arnóbio Marques 310, Santo Amaro, 50100-130 Recife, Pe, Brazil. E-mail: rita_upe@yahoo.com.br. and Virkki, 1978; Yadav and Pillai, 1979) and from $2 \mathrm{n}=12$ to $2 \mathrm{n}=20$ in the Dynastinae (Vidal, 1984; Martins, 1994).

Differential techniques have rarely been applied to chromosome studies of the Coleoptera, but data from the species so far analyzed have shown that the autosomal constitutive heterochromatin $(\mathrm{CH})$ is preferentially located on pericentromeric region and is less frequent on interstitial and telomeric regions while the position of sex chomosome constitutive heterochromatin is more variable in that it may be pericentromeric or entirely heterochromatic (Vidal et al., 1977; Angus, 1983; Drets et al., 1983; Virkki, 1983; Juan and Petitpierre, 1989; Rozek and Lachowska, 2001). Base-specific fluorochromes have provided important information regarding the composition of $\mathrm{CH}$ in coleopteran species of the families Tenebrionidae (Juan and Petitpierre, 1989; Plohl et al., 1993) and Scarabaeidae (Colomba et al., 1996; Colomba et al., 2000; Moura et al., 2003). Data regarding the localization of the nucleolar organizer regions (NORs) in the scarab Phyllophaga (Phytalus) vestita and Lyogenys fuscus obtained by silver nitrate staining and flu- 
orescence in situ hybridization (FISH) have shown that the ribosomal sites are preferentially located on the sex chromosomes (Moura et al., 2003), although in Gymnopleurus sturmi and Phyllophaga (P.) aff capillata (Scarabaeidae), Trotectes intermedius (Geotrupidae), Eriopis connexa (Coccinellidae) and in 19 Zabrus species (Carabidae), the NORs are located on the autosomes (Vitturi et al., 1999; Colomba et al., 2000; Maffei et al., 2000; Sánchez-Géa et al., 2000; Moura et al., 2003).

This study presented in this paper provides detailed kayotypic descriptions of three representative Rutelinae species (Geniates borelli, Macraspis festiva and Pelidnota pallidipennis) and two representative Dynastinae species (Lygirus ebenus and Strategus surinamensis hirtus) with special emphasis on the distribution and variability of constitutive heterochromatin and NORs.

\section{Materials and Methods}

Meiotic chromosomes were obtained from Rutelinae species (Geniates borelli Camerano, 1894 (12 specimens), Macraspis festiva Burmeister, 1844 (6 specimens) and Pelidnota pallidipennis Bates, 1904 (12 specimens) and Dynastinae species (13 Lygirus ebenus De Geer, 1774 and five Strategus surinamensis hirtus Sternberg, 1910). The specimens were male beetles collected from Atlantic Forest sites situated in the northeastern Brazilian state of Pernambuco at $07^{\circ} 48^{\prime} 37^{\prime}$ ' S, $34^{\circ} 27^{\prime} 25^{\prime}$ ' W near the town of Igarassú for G. borelli, P. pallidipennis and L. ebenus and $08^{\circ} 0$ ' $8^{\prime \prime}, 35^{\circ} 1^{\prime} 6$ " W near the town of São Lourenço da Mata for S. s. hirtus and M. festiva. Testicular follicle squashes were made in ethanol and acetic acid (3:1) fixative and the chromosomes stained with $2 \%$ lacto acetic orceína. We also performed C-banding (Sumner, 1972), silver nitrate (Rufas et al., 1987) and AT/GC base pair fluorescence staining (Schweizer et al., 1983). Fluorescent in situ hybridization (FISH) was performed as described by Moscone et al. (1996) using Arabidopsis thaliana 45S rDNA probes (Unfried et al., 1989; Unfried and Gruendler, 1990) nick translation labeled with bio-11-dUTP (Life Technologies) and detected with rat antibiotin antibodies (Dakopatts M0743, Dako) and tetramethyl-rhodamine isothiocyanate (TRITC) conjugated rabbit anti-rat antibodies (Dakopatts R0270, Dako).

\section{Results}

\section{Standard staining and C-banding}

The male karyotypes of most of the species analyzed were $2 \mathrm{n}=20\left(9 \mathrm{II}+\mathrm{X} \mathrm{y}_{\mathrm{p}}\right)$ (Figure 1a, c-f), the exception being $M$. festiva which had a karyotype of $2 \mathrm{n}=18\left(8 \mathrm{II}+\mathrm{Xy}_{\mathrm{p}}\right)$ (Figure 1b). The chromosomes of $G$. borelli, $P$. pallidipennis and L. ebenus were meta-submetacentric and showed a gradual decrease in size. The sex-determining
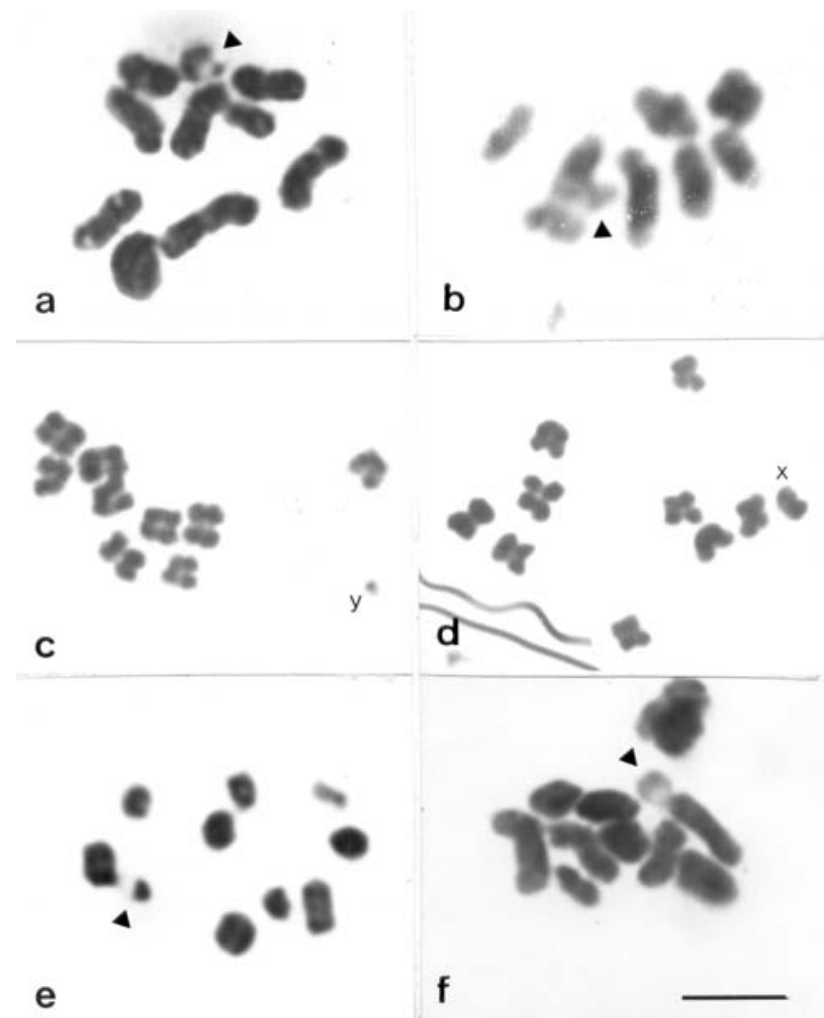

Figure 1 - Meiotic chromosomes stained with acetic orcein. Metaphases I of G. borelli (a) M. festiva (b), L. ebenus (e) and S. s hirtus (f). Note the parachute configuration of the sex pair (arrowheads). Metaphases II of $P$. pallidipennis $(\mathrm{c}, \mathrm{d})$, note the sex chromosomes. Bar $=5 \mu \mathrm{m}$.

mechanism of all the species analized was of the parachute type, with a metacêntric $\mathrm{X}$ chromosome and a diminutive $\mathrm{Y}$ chromosome (Figure 1a, b, e, f).

The C-banding method revealed blocks of constitutive heterochromatin in the pericentromeric region of all the autosomes of the Rutelinae species (Figure 2a-c) while for the Dynastinae species in addition to the pericentromeric blocks a terminal block was noted on a small chromosome of L. ebenus (Figure 2d) and C-banding was absent from one S. s. hirtus (Figure 2e). The X chromosomes of the five species studied were all almost completely heterochromatic and no constitutive heterochromatin blocks were detected in the y chromosome of any of the species (Figure 2b-d). Heterochromatin associations forming chromocenters between autosomal bivalents were observed in the five species analyzed, these associations being first visible during meiotic prophase and persisted until the end of the pachytene phase (Figure 2c).

\section{Fluorochrome staining}

For $G$. borelli $\mathrm{CMA}_{3} / \mathrm{DA} / \mathrm{DAPI}$ staining showed small GC-rich $\mathrm{CMA}_{3}$ positive blocks, coinciding with those visualized by $\mathrm{C}$-banding, in the pericentromeric region of all the chromosomes (Figure $3 \mathrm{a}$ ), but no DAPIpositive blocks were detected in this species (Figure $3 \mathrm{~b}$ ). In 


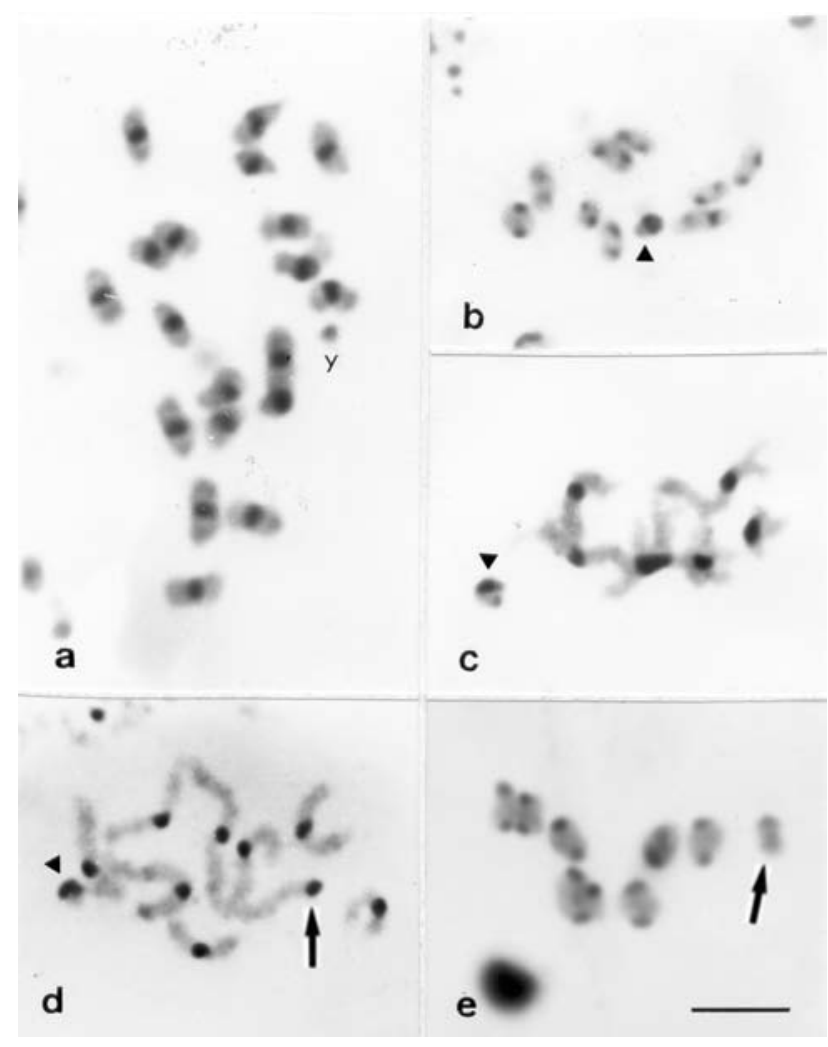

Figure 2 - Constitutive heterochromatin $(\mathrm{CH})$ distribution pattern in the five species studied. C-bands in a spermatogonial metaphase of $G$. borelli (a). Metaphase I of $P$. pallidipennis (b). Pachytene of $M$. festiva (c), note the heterochromatic associations. Diplotene and metaphase I of $L$. ebenus (d) and S. s. hirtus (e). The arrowheads point to an almost completely heterochromatic sex bivalent. The arrows indicate the presence of a terminal CH block in L. ebenus (d) and the absence of labeling in an autosomal bivalent of $S$. s. hirtus (e). Bar $=5 \mu \mathrm{m}$.

contrast, $P$. pallidipennis presented DAPI blocks similar in size and location to those detected by C-banding and the heterochromatin of this species was AT-rich except for a small $\mathrm{CMA}_{3}$-positive block detected in one of the autosomal bivalents and another detected in the sex chromosomes (Figure $3 \mathrm{e}, \mathrm{f}$ ), $\mathrm{CMA}_{3} / \mathrm{DA}$ staining revealed the presence of GC-rich blocks in all chromosomes of the complement except for a small bivalent, but no DAPI-positive blocks were detected in this species.

\section{Silver nitrate staining and FISH}

Amorphous masses corresponding to nucleolar remnants were visualized by silver nitrate staining in the $X y_{p}$ bivalents of $G$. borelli, $P$. pallidipennis, $M$. festiva and $S$. $S$. hirtus (Figure 4 a, c, d, f), while in L. ebenus the labeling was detected on an autosomal pair (Figure 4e). These masses were visible until the end of the pachytene phase or the beginning of the diplotene phase. Silver nitrate also labeled the constitutive heterochromatin blocks (Figure 4a-c, e) and the sex chromosomes showed affinity for silver and continued to be labeled during different phases of meiosis
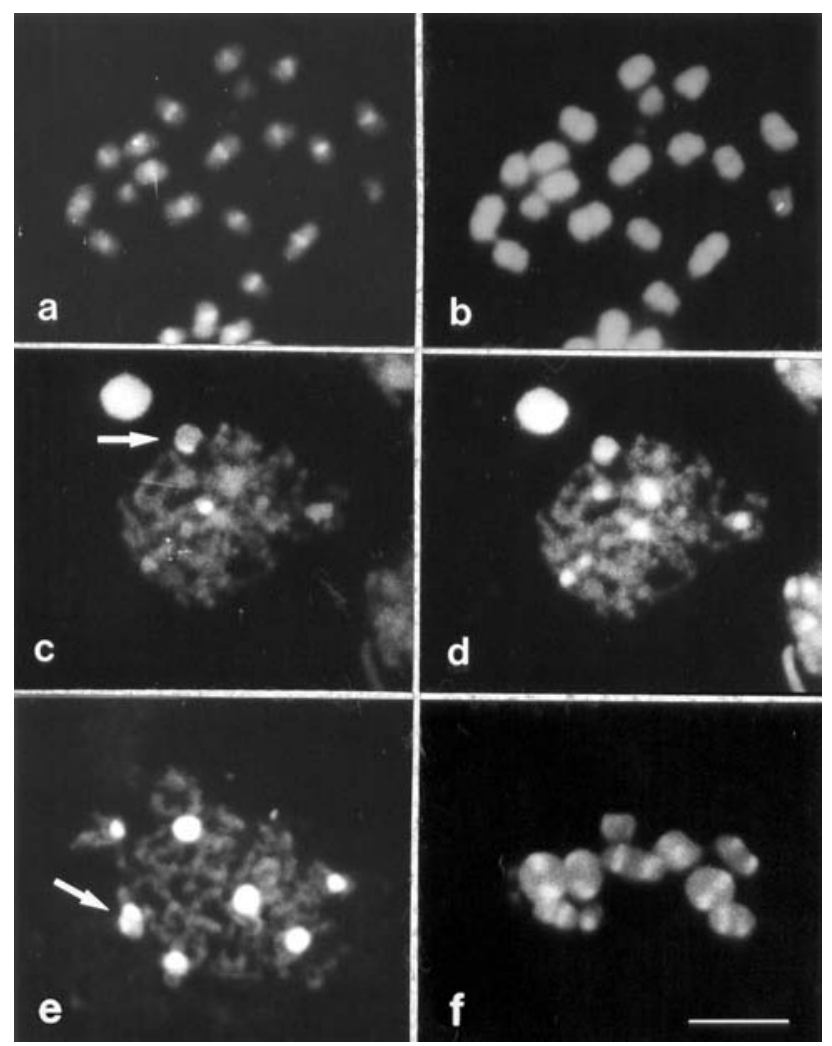

Figure $3-\mathrm{CMA}_{3} / \mathrm{DA} / \mathrm{DAPI}$ staining in $G$. borelli $(\mathrm{a}, \mathrm{b})$ and $P$. pallidipennis (c, d), and double $\mathrm{CMA}_{3} / \mathrm{DA}$ staining in $S$. s. hirtus (e, f). (a, b) Incomplete spermatogonial metaphase $(a, b)$ showing pericentromeric $\mathrm{CMA}_{3}+$ blocks. Initial zygotene (c, d). Note the $\mathrm{CMA}_{3}+$ blocks in the sex pair (arrow) and in an autosomal bivalent (d). Note the associated DAPI+ constitutive heterochromatin blocks. (e, f) pachytene and metaphase I. The arrows in (c-e) indicate the $\mathrm{Xy}_{\mathrm{p}}$ bivalent. Bar $=5 \mu \mathrm{m}$.

(Figure 4b). In the three Rutelinae species, FISH of rDNA genes produced results, which coincided with those, obtained by silver nitrate staining and permitted the identification of rDNA genes on the X chromosome (Figure 5a-c).

\section{Discussion}

We found that G. borelli, P. pallidipennis, L. ebenus and $S$. s. hirtus had the $2 \mathrm{n}=20\left(9 \mathrm{II}+\mathrm{Xy}_{\mathrm{p}}\right)$ karyotype typical of the suborder Polyphaga, but $M$. festiva karyotype of $2 \mathrm{n}=18\left(8 \mathrm{II}+\mathrm{Xy}_{\mathrm{p}}\right)$ which coincided with the karyotype of Macraspis dichroa (Vidal, 1984). Other species of Macraspis are known to have a $2 \mathrm{n}=20$ karyotype (Martins 1994) but with the $X_{p}$ type sex-determining system changed to neoXy system. Karyotypic comparisons $M$. festiva and other species of Macraspis of known cytology suggests that karyotype evolution in this genus might have involved different types of chromosome rearrangements. It is possible that the reduction in the chromosome number observed in $M$. festiva might have been due to a mechanism involving pericentric inversion followed by fusion between autosomes, which would explain the occurrence of karyotypic changes in the absence of alterations in the 
sex-determining system. Changes of this type have been described in the literature and are included in the five types of karyotype evolution proposed for Scarabaeidae by Yadav and Pillai (1979).

a

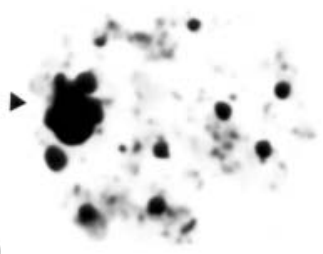

cr.
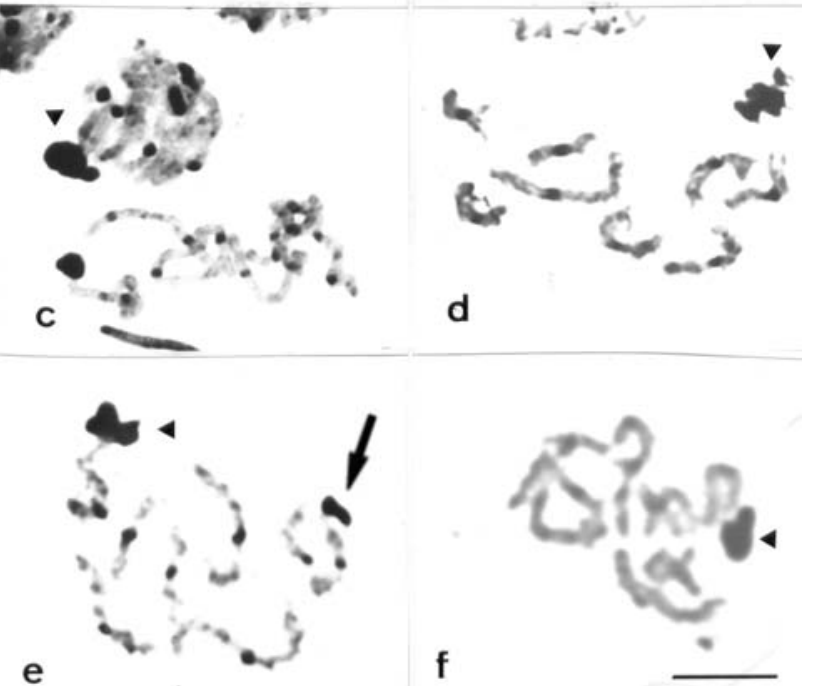

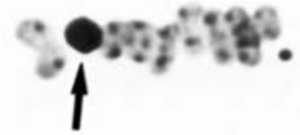

b

f

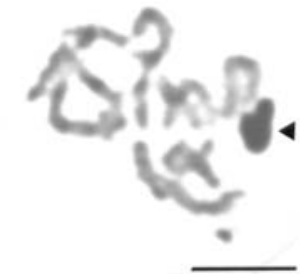

Figure 4 - Silver nitrate staining in the five species analyzed. Pachytene and metaphase I of $G$. borelli $(\mathrm{a}, \mathrm{b})$. Zygotene and initial pachytene of $P$. pallidipennis (c). Final pachytene of $M$. festiva (d). Pachytenes of $L$. ebenus (e) and S. s hirtus (f). Observe the heterochromatic regions and the strongly silver-labeled sex pair (b). The arrows in (b,e) indicate de Xy $\mathrm{p}_{\mathrm{p}}$ bivalent. The arrowheads indicate nucleolar organizer regions. Bar $=5 \mu \mathrm{m}$.
Our results show that in $G$. borelli, $P$. pallidipennis, M. festiva, L. ebenus and S. s. hirtus there was some degree of conservation in terms of the size and location of the $\mathrm{CH}$ blocks as well as a type of heterochromatic association in which chromocenters formed between some autosomal bivalents. It is known that the degree of ectopic pairing between heterochromatic segments that promote the formation of chromocenters varies among different coleopteran species and that this type of association seems to play an important role in nuclear organization and the segregation of meiotic chromosomes (Smith and Virkki, 1978; Drets et al., 1983).

The constitutive heterochromatin of the species analyzed by us was located on the pericentromeric region of the chromosomes, similar observations having been reported for other Scarabaeidae (Vidal and Giacomozzi, 1978; Vidal and Nocera, 1984). This pattern of distribution has been described for most coleopteran species studied by C-banding (Virkki, 1983; Rozek and MaryanskaNadachowska, 1991; Rozek and Rudek, 1992), although telomeric blocks in addition to pericentromeric ones have been observed in the tenebrionid Misolampus goudoti (Juan and Petitpierre, 1989) and exclusively telomeric blocks in the carabid Bembidion minimum (Rozek and Rudek, 1992), with extra-heterochromatic segments having been reported in the scarabaeid Bubas bison (Colomba et al., 1996).

In our study, $\mathrm{CMA}_{3}$ and DAPI staining revealed that qualitative heterogeneity in the constitutive heterochromatin of $G$. borelli and $S$. $s$ hirtus we found $\mathrm{CMA}_{3}$ positive blocks indicating GC-rich constitutive heterochromatin, but in Pelidnota palidipennis we found two types of constitutive heterochromatin, a DAPI positive type
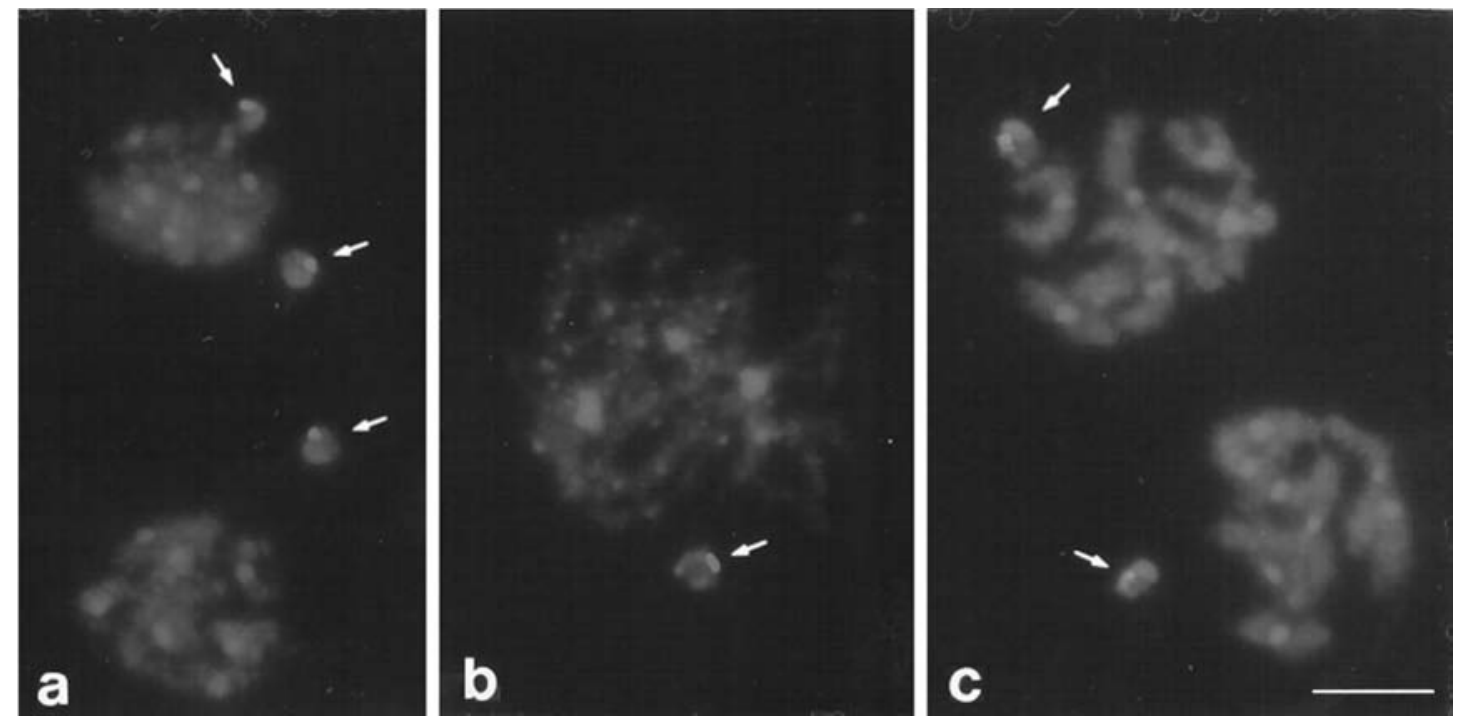

Figure 5 - Fluorescent in situ hybridization (FISH) in the three Rutelinae species. Zygotenes of G. borelli (a), P. pallidipennis (b) and M. festiva (c). Note the rDNA sites (arrows). Bar $=5 \mu \mathrm{m}$. 
evenly distributed throughout the karyotype and a $\mathrm{CMA}_{3}$ positive type restricted to one small block located on the sex pair (probably the X chromosome) and another small block located on one of the autosomal bivalents. Reports on the use of base-specific fluorochromes in Scarabaeidae are still scarce, but different patterns have been found in some species. For example, in Gymnopleurus sturni (Vitturi et al 1999) and Thorectes intermedius (Colomba et al 2000) GC-rich sequences were detected in all the chromosomes while Lyogenys fuscus presented AT-rich sequences in every karyotype complement studied (Moura et al., 2003).

Data regarding the location of NORs in Coleoptera have suggested that a pair of nucleolar organizer autosomes is widely distributed in this order (Virkki, 1983; Virkki et al., 1984). In representatives of the family Scarabaeidae rDNA sites are generally found on the X chromosome, although sites located on autosomes have been reported for Phyllophaga (Phyllophaga) aff capillata and Gymnopleurus sturni (Moura et al., 2003; Colomba et al., 2000). In G. borelli, P. pallidipennis, M. festiva and $S$. $S$ hirtus we found that the NOR was associated with the sex bivalent, and this confirmed for G. borelli, P. pallidipennis, M. festiva by our in situ hybridization using the $45 \mathrm{~S}$ rDNA probe.

Studies analyzing the development and segregation of the $\mathrm{Xy}_{\mathrm{p}}$ chromosome in some curculionid species have shown that, even when the NORs are autosomal, the lumen of the sex bivalent is filled from diakinesis to anaphase I with proteinaceous substances which have an affinity for silver and which probably resemble substances present in the synaptonemal complex and chromosome skeleton. It has been proposed by Virkki et al. $(1990 ; 1991)$ that these substances function as an adhesive and therefore control the correct disjunction of the sex chromosomes.

In the Scarabaeidae species analyzed we found that the sex bivalent remained silver labeled after the nucleolus disappeared, suggesting that the $\mathrm{Xy}_{\mathrm{p}}$ association is not necessarily due to the presence of the NOR, but rather to the presence of argyrophilic proteins distributed within the heterochromatin of these species. Argyrophilic proteins have also been observed in the scarabaeid species Thorectes intermedius (Vitturi et al., 1999), Gymnopleurus sturni (Colomba et al., 2000), Phyllophaga (Phytalus) vestita, Phyllophaga (Phyllophaga) aff capillata and Lyogenys fuscus (Moura et al., 2003) and their presence appears not to depend on the base composition of $\mathrm{CH}$, further studies being needed to establish the real biochemical composition of scarabeoid beetle heterochromatin and explain the positive reaction to silver staining.

Our results show that in the species studied by us there was a clear relationship between the NOR and the sex chromosomes, with silver staining and FISH demonstrating that NORs are preferentially located on the sex pair. Al- though not indicating the direct participation of the NOR in the formation of the $\mathrm{Xy}_{\mathrm{p}}$ bivalent, this relationship demonstrates the apparent conservation of the location of the rDNA sites on the $\mathrm{X}$ chromosomes in representatives of the family Scarabaeidae.

\section{Acknowledgements}

The authors are indebted to Dr. Sérgio Ide, (Insitute of Biology, São Paulo) for the taxonomic identification of the species analyzed in this study; Dr. Marcelo Guerra (Department of Botany, UFPE) for providing the infrastructure for performing the FISH experiments; Dr Neide Santos (Department of Genetics, UFPE) for critical reviewing of the manuscript; and Francisca Tavares de Lira for technical assistance. The study was supported by Conselho Nacional de Desenvolvimento Científico e Tecnológico (CNPq) and Fundação de Amparo à Ciência e Tecnologia do Estado de Pernambuco (FACEPE).

\section{References}

Angus RB (1983) Separation of Helophorus grandis, maritimus and occidentalis sp. n. (Coleoptera, Hydrophilidae) by banded chromosome analysis. Syst Entomol 8:1-13.

Colomba MS, Monteresino E, Vitturi R and Zunino M (1996) Characterization of mitotic chromosomes of the scarab beetles Glyphoderus sterquilinus (Westwood) and Bubas bison (L.) (Coleoptera, Scarabaeidae) using conventional and banding techniques. Biol Zentbl 115:58-70.

Colomba MS, Vitturi R and Zunino M (2000) Karyotype analyzes, banding, and fluorescent in situ hybridization in the Scarab beetle Gymnopleurus sturmi McLeady (Coleoptera, Scarabaeoidea, Scarabaeidae). The Journal of Heredity 91:260-264.

Drets ME, Corbella E, Panzera F and Folle GA (1983) C-banding and non-homologous association II. The "parachute" $\mathrm{Xy}_{\mathrm{p}}$ sex bivalent and the behaviour of heterochromatic segments in Epilachna paenulata. Chromosoma 88:249-255.

Endrödi S (1985) The Dynastinae of the World. Dr. W. Junk, Budapest, 801 pp, xlvi pls.

Juan C and Petitpierre E (1989) C-banding and DNA content in seven species of Tenebrionidae (Coleoptera). Genome 32:834-839.

Maffei EMD, Gasparino E and Pompolo SG (2000) Karyotypic characyerization by mitosis, meiosis and C-banding of Eriopis connexa Mulsant (Coccinellidae, Coleoptera, Polyphaga), a predator of insect pests. Hereditas 132:79-85.

Martins VG (1994) The chromosomes of five especies of Scarabaeidae (Polyphaga, Coleoptera). Naturalia 19:89-96.

Morón MA, Ratcliffe BC and Deloya. C (1997) Atlas de los escarabajos de Mexico. Coleoptera, Lamelicornia. V. 1 Familia Melolonthidae, Subfamilias Rutelinae, Dynastinae, Cetoniinae, Trichiinae, Valginae y Melolonthinae. Xalapa, Sociedad Mexicana de Entomologia, A.C., xvi +280 pp.

Moscone EA, Matzke MA and Matzke AJM (1996) The use of combined FISH/GISH in conjunction with DAPI counterstaining to identify chromosomes containing transgene inserts in amphidiploid tobacco. Chromosoma 105:231-236. 
Moura RC, Souza M.J, Melo NF and Lira-Neto AC (2003) Karyotypic characterization of representatives from Melolonthinae (Coleoptera, Scarabaeidae): Karyotypic analysis, banding and fluorescent in situ hybridization (FISH). Hereditas 138:200-206.

Plohl M, Lucijanic-Justic V, Hugarkovic D, Petitpierre E and Juan C (1993) Satellite DNA and heterochromatin of the flour beetle Tribolium confusum. Genome 36:467-675.

Rozek M and Lachowska D (2001) C-bands on chromosomes of four beetle species (Coleoptera, Carabidae, Silphidae, Elateridae, Scarabaeidae). Folia Biologica 49:3-4.

Rozek M and Maryanska-Nadachowska A (1991) Studies on C-banding karyotype and meiosis of Harpalus affinis (Shrank 1781) (Coleoptera, Carabidae). Caryologia 44:317-323.

Rozek M and Rudek Z (1992) Karyotype analysis and C-banding pattern in two species of carabid (Coleoptera, Carabidae). Folia biologica 40:47-52.

Rufas JS, Giménez-Ábian J, Suja JA and Garcia de la Vega C (1987) Chromosome organisation in meiosis revealed by light microscope analysis of silver-stained "cores". Genome 29:706-712.

Sánchez-Gea JF, Serrano J and Galián J (2000) Variability in rDNA loci in Iberian species of the genus Zabrus (Coleoptera, Carabidae) detected by fluorescence in situ hybridization. Genome 43:22-28.

Schweizer D, Mendelak M, White MJD and Contreras N (1983) Cytogenetics of the parthenogenetic grasshopper Warramaba virgo and its bisexual relatives. X. Pattern of fluorescent banding. Chromosoma 88:227-236.

Smith SG and Virkki N (1978) Coleoptera. In: John B (ed) Animal Cytogenetics Borntraeger, Berlin, Stuttgart, 366 pp.

Sumner AT (1972) A simple technique form demonstrating centromeric heterochromatin. Exp Cell Res 75:304-306.

Unfried I and Gruendler P (1990) Nucleotide sequence of the 5.8S and 25S rRNA genes and of the internal transcribed spacers from Arabdopsis thaliana. Nucleic Acids Res 18:4011.
Unfried I, Stocker U and Gruendler P (1989) Nucleotide sequence of the 18S rRNA gene from Arabdopsis thaliana. Nucleic Acids Res 17:7513.

Vidal OR (1984) Coleoptera from Argentina. Genetica 65:235239.

Vidal OR and Giacomozzi RO (1978) Los cromosomas de la subfamilia Dynastinae (Coleoptera, Scarabaeidae). Las bandas C en Enema pan (Fabr.). Physis 38:113-119.

Vidal OR and Nocera CP (1984) Citogenética de la tribu Eucranini (Coleoptera, Scarabaeidae). Estudios convencionales y con bandeo C. Physis 42:83-90.

Vidal OR, Giaccomozzi RO and Riva R (1977). Los cromosomas de la subfamilia Dynastinae (Coleoptera, Scarabaeidae). I. Inversión pericéntrica en Diloboderus abderus (Sturm) 1862. Physis 37:303-309.

Virkki N (1983) Banding of Oedionychna (Coleoptera, Alticinae) chromosomes: C- and Ag-bands. J. Agric. Univ. Puerto Rico 67:221-225.

Virkki N, Flores M and Escudero J (1984) Structure, orientation and segregation of the sex trivalent in Pyrophorus luminosus (Coleoptera, Elateridae). Can J Genet Cytol 26:326-330.

Virkki N, Mazzella C and Denton A (1990) Staining of substances adjacent to the $\mathrm{Xy}_{\mathrm{p}}$ sex bivalent of some weevils (Coleoptera, Curculionidae). J Agric Univ Puerto Rico 74:405-418.

Virkki N, Mazzella C and Denton A (1991) Silver staining of the coleopteran $\mathrm{Xy}_{\mathrm{p}}$ sex bivalent. Cytobios 67:45-63.

Vitturi R, Colomba MS, Barbieri R and Zunino M (1999) Ribosomal DNA location in the scarab beetle Thorectes intermedius (Costa) (Coleoptera, Geotrupidae) using banding and fluorescent in-situ hybridization. Chromosome Research 7:255-260.

Yadav JS and Pillai RK (1979) Evolution of Karyotypes and phylogenetic relationships in Scarabaeidae (Coleoptera). Zool Anz Jena 202:105-118.

Associate Editor: Yatiyo Yonenaga-Yassuda 